\title{
Survey Perilaku Merokok Pada Remaja SMA di Malang
}

\section{Yuyud Wahyudi $^{1}$}

1. STIKes Widya Cipta Husada, Kepanjen Malang

Smoking was a community health problem in Indonesia. The high

Korespondensi

Keywords:

Adolescents, smoking, triggers of smoking prevalence of smoking in adolescents is closely related to the sorounding environment as a trigger for smoking. This study aims to explore trigger of smoking among adolescents in a district in Malang, East Java. The results of this study will be very useful as a basis in the initiation program to stop smoking for adolescents in Indonesia. Descriptive research with cross sectional approach was done on 210 high school students as respondents. By using the simple random sampling method, the respondents were asked to fill out the questionnaire that has been provided. Among $94 \%$ of respondents $(\mathrm{n}=198), 15.2 \%(95 \%$ CI $[10.7,20,9])$ were identified as regular smokers. The mean age for first-time smoking was 12.1 years with a standard deviation of 2.49 (95\% CI [11.45, 12.76]). Trigger for smoking in adolescents in this study was coffee shop $(43.3 \%, 95 \%$ CI $[26,2,62,2])$, saw smoking friends $(16 \%, 95 \%$ CI $[13.3,46.1])$, during examination season (33.3\%, 95\% CI $[18,2,52,8])$. Application and implementation of smoking bans in public areas may help reduce appearance the triggers for adolescents.

\begin{abstract}
Abstrak
Perilaku merokok adalah masalah kesehatan komunitas di Indonesia. Tingginya prevalensi merokok pada remaja sangat berhubungan dengan lingkungan sekitar tempat tinggal sebagai pemicu untuk merokok. Penelitian ini bertujuan untuk menggali pemicu merokok pada remaja di sebuah Kecamatan di Kabupaten Malang, Jawa Timur. Hasil penelitian ini akan sangat berguna sebagai dasar dalam inisiasi program berhenti merokok bagi remaja di Indonesia. Metode penelitian deskriptif dengan pendekatan crosssectional dilakukan pada 210 orang siswa SMA sebagai responden. Dengan menggunakan metode simpel random sampling, para responden diminta untuk mengisi kuesioner yang telah disediakan. Diantara 94\% responden $(n=198)$, sebanyak 15.2\% (95\% CI [10.7,20.9]) teridentifikasi sebagai perokok tetap. Rata rata usia untuk pertama kali merokok adalah 12.1 tahun dengan nilai standard deviasi 2.49 (95\% CI $[11.45,12.76])$. Trigger untuk merokok pada remaja dalam penelitian ini adalah warung kopi $(43.3 \%$, 95\% CI $[26.2,62.2])$, melihat teman merokok (16\%, 95\% CI [13.3, 46.1]), saat musim ujian $(33.3 \%, 95 \%$ CI $[18.2,52.8])$. Aplikasi dan implementasi larangan merokok ditempat umum mungkin dapat membantu menurunkan pemicu merokok bagi remaja.
\end{abstract}

\section{Kata kunci : remaja, merokok, pemicu merokok}




\section{Latar Belakang}

Sebagai salah satu negara dengan masyarakat pengkonsumsi rokok yang tinggi di dunia (Eriksen et al., 2012; Lian dan Dorothea, 2014), di Indonesia telah banyak dilaporkan insiden berbagai penyakit akibat perilaku merokok (Lian \& Dorothea, 2014; WHO, 2012). Namun demikian, prevalensi merokok di kalangan usia 15 tahun keatas tetap tinggi $(34,8 \%)$ (WHO, 2012). Strategi yang tepat untuk program berhenti merokok sangat penting untuk menurunkan angka perokok dan mencegah remaja perokok memasuki ketergantungan nikotin ketika mereka telah memasuki usia dewasa (Karpinsky et al., 2010). Kabupaten Malang adalah sebuah kabupaten yang masuk dalam sepuluh besar Kabupaten di Indonesia yang memiliki proporsi perokok perokok 10 tahun ke atas (27,6\%) (Balitbangkes, 2008). Kurangnya pelaksanaan peraturan pemerintah mungkin berkorelasi dengan tingginya persentase perokok di kalangan remaja di Kabupaten Malang (Dinas Kesehatan Kabupaten Malang, 2015). Penelitian ini bertujuan untuk menggali informasi terkait pemicu merokok pada sebuah Kecamatan di Kabupaten Malang, Jawa Timur.

\section{Metode}

Penelitian ini menggunakan metode deskriptif dengan pendekatan cross-sectional, pemilihan sampel dilakukan dengan menggunakan simple random sampling. Data Sekolah Menengah Atas beserta daftar nama siswa didapatkan dari Dinas
Pendidikan Kabupaten Malang, yakni sebanyak 2.245 siswa SMA yang akan digunakan sebagai populasi, kemudian 150 siswa perlu dijadikan sampel. Dengan pertimbangan saran penelitian sebelumnya, $40 \%$ dari ukuran sampel telah ditambahkan untuk meningkatkan responce rate kuesioner, 210 sampel. Instrumen dalam penelitian ini adalah self reported questionaire. Semua item pertanyaan dalam kuesioner tersebut diperoleh melalui literature review, informasi berdasarkan studi, dan diskusi dengan ahli. Instrumen terdiri dari 7 item pertanyaan yang berkaitan dengan data sosio-demografis, dan 26 item pilihan ganda menjawab pertanyaan untuk memeriksa tiga jenis pemicu rokok. Uji validitas kuesioner menggunakan I-CVI, telah dilakukan oleh dua ahli keperawatan dari Fakultas Keperawatan Universitas Khon Kaen - Thailand, dan tiga orang ahli di bidang keperawatan dan kesehatan masyarakat dari berbagai institusi di Indonesia. Dari uji validitas kuesioner didapatkan rata-rata perhitungan I-CVI sebesar 0,95.

Persetujuan secara verbal diperoleh berdasarkan kesediaan responden untuk mengembalikan kembali instrumen yang dijawab ke kotak kuesioner yang dirancang yang disediakan oleh peneliti di setiap sekolah. Selanjutnya, ada 198 responden (94\%) yang telah mengembalikan kuesioner. Data dalam penelitian ini dianalisis dengan menggunakan program SPSS 21.0 dan STATA untuk windows, termasuk statistik 
deskriptif (Mean, Median, Standard Deviation, IQR) untuk data sosial demografi dan pemicu merokok. Prosentase proporsi dan 95\% Confidence Interval untuk proporsi juga digunakan untuk memperkirakan prevalensi.

\section{Table 1. Karakteristik Responden}

\begin{tabular}{|c|c|c|}
\hline Variable items & $\begin{array}{c}\text { Frequency } \\
(n=198)\end{array}$ & $\begin{array}{c}\text { Percentage } \\
(\%)\end{array}$ \\
\hline \multicolumn{3}{|l|}{ Gender } \\
\hline Male & 88 & 44.4 \\
\hline Female & 110 & 55.6 \\
\hline Age & & $\begin{array}{l}\text { Mean } \pm \\
\text { SD } \\
16.37 \pm \\
1.08 \\
\text { Min }=15.0 \\
0 \\
\text { Max }= \\
19.00\end{array}$ \\
\hline $15-17$ & 163 & 82.3 \\
\hline $18-20$ & 35 & 17.7 \\
\hline \multicolumn{3}{|l|}{ Ethnicity } \\
\hline Javanese & 186 & 93.9 \\
\hline Madura & 5 & 2.5 \\
\hline Papua & 3 & 1.5 \\
\hline Sumatra & 2 & 1 \\
\hline Sundanese & 1 & .5 \\
\hline Balinese & 1 & .5 \\
\hline \multicolumn{3}{|l|}{$\begin{array}{l}\text { Environmental } \\
\text { smoke }\end{array}$} \\
\hline Father smoke & 98 & 49.5 \\
\hline $\begin{array}{l}\text { Other adult } \\
\text { (except father) } \\
\text { people in family } \\
\text { smoke }\end{array}$ & 49 & 24.7 \\
\hline $\begin{array}{l}\text { Parents permitting } \\
\text { to smoke }\end{array}$ & 5 & 2.5 \\
\hline Friends smoke & 180 & 90.9 \\
\hline
\end{tabular}

\section{Hasil}

Di antara 198 siswa, 93,9\% adalah berasal dari suku Jawa. Usia rata-rata responden adalah 16,37 tahun $(\mathrm{SD}=1,10)$. Hampir semua responden melaporkan memiliki teman perokok (90,9\%).
Prevalensi merokok saat ini adalah 12,7\%. Usia rata-rata perokok yang pernah ada adalah 12,10 $(\mathrm{SD}=2,49)$. Tidak pernah ada perokok $(70,7 \%)$, alasan terbanyak adalah alasan kesehatan (76,3\%). Hampir separuh perokok (48,8\%) sudah berhenti merokok karena alasan kesehatan mereka (67,9\%). Melakukan aktivitas atau olah raga (64,3\%) merupakan faktor pendukung keberhasilan berhenti merokok (tabel 1).

Table 2. Faktor Pemicu Merokok

\begin{tabular}{lccc}
\hline \multicolumn{1}{c}{ Variable items } & Number & Percent & $\mathbf{9 5 \%}$ CI \\
& & & \\
$\begin{array}{l}\text { Places as triggers of } \\
\text { smoking (n=30) }\end{array}$ & & & \\
$\begin{array}{l}\text { Canteen out of school } \\
\quad \text { Never }\end{array}$ & 9 & 30.0 & $15.7-49.5$ \\
$\quad$ Sometimes & 15 & 50.0 & $31.8-68.1$ \\
$\quad$ Always & 6 & 20.0 & $8.8-39.2$ \\
Coffee shop & & & \\
$\quad$ Never & 6 & 20.0 & $8.8-39.2$ \\
$\quad$ Sometimes & 11 & 36.7 & $20.8-56.0$ \\
$\quad$ Always & 13 & 43.3 & $26.2-62.2$ \\
$\begin{array}{l}\text { Persons as triggers of } \\
\text { smoking (n=30) }\end{array}$ & & & \\
Friends smoking & & & \\
$\quad$ Never & 8 & 26.7 & $13.3-46.1$ \\
$\quad$ Sometimes & 17 & 56.7 & $37.7-73.7$ \\
$\quad$ Always & 5 & 16.7 & $6.7-35.6$ \\
Events as triggers of \\
smoking (n=30)
\end{tabular}

Berkaitan dengan pemicu untuk merokok (tabel 2), warung kopi diidentifikasi sebagai tempat yang 
selalu membuat responden ingin untuk segera merokok (43\%), diikuti oleh kantin di luar sekolah (20\%). Berkumpul dengan teman yang merokok juga diidentifikasi untuk selalu (16,7\%) kadangkadang $(56,7 \%)$ memicu untuk segera merokok. Selama musim ujian sekolah juga diidentifikasi sebagai pemicu untuk merokok yang selalu membuat mereka ingin merokok $(33,3 \%)$.

\section{Diskusi}

Prevalensi remaja perokok pada penelitian ini lebih tinggi daripada temuan penelitian lainnya di Indonesia (Balitbangkes, 2013) dan negara-negara lain (Sirirassamee et al., 2011; Rozy et al., 2005). Usia inisiasi merokok pada remaja dalam penelitian ini juga cenderung semakin muda $(\mathrm{M}=$ 12,1, $\mathrm{SD}=2,49)$ dibandingkan penelitian sebelumnya (Martini \& Sulistyowati, 2005; Ebirim, dkk, 2014; Sirirassamee et al., 2011). Prevalensi merokok yang tinggi di kalangan remaja pada suku Jawa mungkin karena perilaku merokok dikaitkan sebagai simbol kedewasaan di antara laki-laki ( $\mathrm{Ng}$ et al., 2007). Bagi anak laki-laki Jawa, perilaku merokok umum diperkenalkan kepada mereka sejak awal masa usia hampir sepanjang hari mereka ( $\mathrm{Ng}$ et al, 2007). Adanya upaya program penyadaran perilaku dengan pendekatan konteks budaya mungkin akan efektif untuk membantu menurunkan prevalensi perokok pada remaja.

Dalam penelitian ini menunjukkan bahwa warung kopi merupakan tempat yang selalu memicu remaja untuk merokok (43\%), diikuti oleh kantin di luar sekolah (20\%). Hasil penelitian yang serupa juga disampaikan oleh Oksuz et al (2007) pada remaja di Turki. Bagi sebagaian besar pria suku Jawa, merokok di warung kopi menjadi sarana mediator sosialisasi dengan teman maupun kerabat dalam keseharian (Adi, T., 2015). Apakah remaja yang terpicu untuk merokok di warung kopi adalah meniru orang dewasa sebagaimana yang diulas dalam Social Learning Theory dari Albert Bandura (1970) atau untuk bersosialisasi dengan teman sebaya masih belum bisa dijelaskan dalam penelitian ini, oleh karena itu penelitian lebih lanjut masih diperlukan (Asri, A. 2018).

Paparan perilaku merokok dari teman perokok selalu (16,7\%) kadang-kadang (56,7\%) memicu remaja untuk merokok. Temuan ini Didukung oleh pernyataan dari beberapa penelitian sebelumnya bahwa paparan dari perokok lain akan memicu seseorang untuk menyalakan rokok (Burton et al., 2015; Krukowski et al., 2005; Gutch et al., 2010). Teman-teman yang merokok memberikan pemicu dan bala bantuan yang solid untuk perilaku merokok (O'Loughlin et al., 2003). Salah satu penelitian kualitatif pada pelajar Sekolah Menengah Atas di Jawa Tengah menunjukkan bukti bahwa kehadiran perokok lain adalah pemicu merokok, dengan ungkapan "banyak teman saya merokok, oleh karena itu saya merasa ingin merokok" dan "ketika saya melihat guru saya merokok di sekolah, saya juga ingin merokok "( $\mathrm{Ng}$ et al., 2007). 
Berkaitan dengan acara sebagai pemicu untuk merokok, musim ujian sekolah diidentifikasikan sebagai pemicu yang selalu membuat mereka perlu merokok (33,3\%), Dalam peristiwa ujian mungkin berkorelasi dengan perasaan stres. Beberapa penelitian sebelumnya menyatakan bahwa peristiwa stres cenderung membuat orang untuk merokok (Burton et al., 2015; Krukowsky et al., 2005; Naiura et al., 2002; Yang et al., 2005).

\section{Kesimpulan}

Prevalensi merokok di kalangan remaja di daerah ini nampaknya tidak berbeda dengan temuan lain dari penelitian lain di Indonesia. Namun, usia inisiasi merokok dalam penelitian ini menjadi lebih muda. Beberapa lingkungan sosial tertentu juga memainkan peran penting sebagai pemicu untuk merokok bagi remaja.

Pengembangan program pencegahan dan penghentian perilaku merokok yang komprehensif bagi secara komprehensif dengan melibatkan peran orang tua, teman sebaya, sekolah, perawat kesehatan masyarakat, dan departemen pemerintah terkait dapat dilakukan berdasarkan data yang ada penelitian ini. Selanjutnya program tersebut harus diperkenalkan sejak mereka memasuki sekolah dasar.

Pendekatan budaya untuk menetralisir persepsi tentang perilaku merokok di kalangan masyarakat Jawa mungkin dapat dilakukan memasukkan didalam kurikulum pembelajaran sebagai upaya pencegahan dan penghentian merokok. Seperti masukan dan saran dari berbagai penelitian serupa sebelumnya, bahwa pemerintah perlu utnuk segera melakukan ratifikasi FCTC WHO guna mengendalikan penggunaan tembakau di Indonesia.

\section{Daftar Pustaka}

Adi, T. L. (2015). Inspirasi Dari Kopi dan Rokok. Minum Kopi.com. Retreived on April 24 $4^{\text {th }}$, 2016 from http://www.minumkopi.com/inspirasidari-kopi-dan-rokok

Aditama, T.Y., Pradono, J., Rahman, K., Warren, C.W., Jones, N.R., Asma, S., Lee, J. (2008). Linking Global Youth Tobacco Survey (GYTS) Data to the WHO Framework Convention on Tobacco Control: The Case for Indonesia. Preventive Medicine, 47 (Suppl 1), 511-514.

Asri, A. (2018). Community Capacity: A Concept Analysis. Jurnal Keperawatan Muhammadiyah, 2(1).

Balitbangkes. (2008). Riset Kesehatan Dasar Propinsi Jawa Timur: Laporan Nasional 2007. Surabaya: Departemnen Kesehatan Republik Indonesia.

Balitbangkes. (2013). Riset Kesehatan Dasar: Laporan Nasional 2013. Jakarta: Departemen Kesehatan Republik Indonesia.

Bancej, C., O’Louglin, J., Platt, R.W., Paradis, G., Gervais, A. (2007). Smoking cessation attempts among adolescent smokers: a systematic review of prevalence studies. Tob Control,16 (6), e8.

Burton, S., Hoek, J., Nesbit, P., Khan, A. (2015). "Smoking is bad, it's not cool...yet I'm still doing it": Cues for tobacco consumption in a 'dark' market. Journal of Business Research. 68 (10), $2067-2074$.

Ebirim, C. I. C., Amadi, A. N., Abanobi, O. C., Iloh G U P. (2014). The Prevalence of Cigarette Smoking and Knowledge of Its Health 
Implications among Adolescents in Owerri, South - Eastern Nigeria. Health, 6(12),1532-1538.

Eriksen, M., Mackay, J., Ross, H. (2012). The Tobacco Atlas. $4^{\text {th }}$ ed. Georgia: American Cancer Society.

Eska, S.A. (2015). Smoking Problem In Malang District [Interview]. Staff of Health Promotion Department, Health Department of Malang District; 21 June 2015.

Fiore, M.C., Jaén, C.R., Baker, T.B. (2008) Treating Tobacco Use and Dependence: 2008 Update. Clinical Practice Guideline. Rockville, MD: U.S. Department of Health and Human Services. Public Health Service.

Gucht, V. D., G.V.,Van den Bergh, O., Beckers, T., Vansteenwegen, D. (2010). Smoking behavior in context: Where and when do people smoke?. J Behav. Ther. \& Exp. Psychiat, 41(2), 172-177.

Hartatik, S. (2015). Implementation of Usaha Kesehatan Sekolah in Kepanjen Sub District [Interview]. Chairman of The Health School Promotion in Kepanjen Sub - District, Kepanjen Primary Health Care; 17 June 2015.

Krainuwat, K. (2005). Smoking Initiation Prevention Among Adolescentss: Implications for Community Health Nursing Practice. Journal of Community Health Nursing, 22(4), 195-204.

Krukowski, R.A.,Solomon, L.J., Naud, S. (2005). Triggers of Heavier and Lighter Cigarette Smoking in College Students. Journal of Behavioral Medicine, 28 (4), 333 - 345.

Kumboyono., Sahar, J., Winarsih, W. (2008). Pengalaman Perokok Rendah Tar dan Nikotin Di Kota Malang. Jurnal Keperawatan Indonesia, $12(2), 91-99$.

Lian, T.Y., Dorothea U. (2014). The ASEAN Tobacco Control Atlas, $2^{\text {nd }}$ ed. Southeast Asia Tobacco Control Alliance. Retreived on April $26^{\text {th }}$, 2015 from http://seatca.org/dmdocuments/2nd\%20Edition
The $\% 20$ ASEAN\%20Tobacco\%20Control\%20Atla s Final $\% 20$ Version.pdf

Martini, S., \& Sulistyowati, M. (2005). The Determinants Of Smoking Behavior Among Adolescents In East Java Province, Indonesia. a Background Paper prepared for the World Bank Study on the Economics of Tobacco and Tobacco Control in Indonesia, with financial support from SIDA and US CDC/OSH. New York : The International Bank for Reconstruction and Development / The World Bank.

Martini, S., \&Sulistyowati, M. (2005). The Determinants Of Smoking Behavior Among Adolescents In East Java Province, Indonesia. a Background Paper prepared for the World Bank Study on the Economics of Tobacco and Tobacco Control in Indonesia, with financial support from SIDA and US CDC/OSH. New York : The International Bank for Reconstruction and Development / The World Bank

Niaura, R., Shadel, W.G., Britt, D.M., Abrams, D.B. (2002). Response To Social Stress, Urge To Smoke, And Smoking Cessation. Addictive Behaviors, 27(2), 241-250.

Ng, N., Wienehall, L., Ohman, A. (2007). 'If I don't smoke, I'm not a real man'-Indonesian teenage boys' views about smoking. Health Education Research, 22(6), 794-804.

O'Loughlin, J. Karp,I. Koulis, T. Paradis, G. Difranza, J. (2009). Determinants of First Puff and Daily Cigarettes Smoking in Adolescents. American Journal of Epidemiology, 170 (5), 585 $-587$.

Oksuz, E., Mutlu, E.T., Malhan. S. (2007). Characteristics Of Daily And Occasional Smoking Among Youths. Public Health, 121 (5), 349-356 Owing , J.H. (2005). Trend in Smoking and Health Research. Nova Science Publisher. Inc.

Park S, MD.(2011). Smoking and Adolescent Health. Department of Pediatrics, Korea University 
College of Medicine, Seoul, Korea. Korean J Ped, 54(10), 401-404.

Robinson, L.A.( 2006). Changes in Adolescents Sources of Cigarettes. Journal of Adolescent Health, 39(6), 861-867.

Rozy, S. Akhtar, S. Ali, S. and Khan, J. (2005). Prevalence and Factors associated with current smoking among high school adolescents in Karachi, Pakistan. Southeast Asian Journal Tropical Medicine Public Health, 36 (2), 498 504.

Rudatsikira, E., Dondog, J., Siziya, S., Muula, A. S. (2008). Adolescent Cigarette Smoking In Mongolia. Singapore Medical Journal, 49(1), 5762.

Sirirassamee, T., Sirirassamee, B., Borland R., Omar, M., Driezen, P.(2011). Smoking Behavior among Adolescents in Thailand and Malaysia. Southeast Asian J Trop Med Public Health, 42 (1), $218-224$.

Sussman,S., Sun, P., Dent, C.W.(2006). A MetaAnalysis of Teen Cigarette Smoking Cessation. Health Psychology, 25 (5), 549-557.

Tandalitin, H., and Luetge, C. (2013). Civil Society and Tobacco Control in Indonesia: The Last Resort. The Open Ethics Journal, 7 (1), 11 18.

Sirirassamee, T., Sirirassamee, B., Borland R., Omar, M., Driezen, P.(2011). Smoking Behavior Among Adolescents In Thailand And Malaysia. Southeast Asian J Trop Med Public Health, 42 (1) $218-224$.

Sussman,S., Sun, P., Dent, C.W.(2006). A MetaAnalysis of Teen Cigarette Smoking Cessation. Health Psychology 25 (5), 549-557.

World Health Organization. (2012). Global Adult Tobacco Survey (GATS): Indonesia report 2011. Retrieved on July $2^{\text {nd }}, 2015$ from http://www.who.int/tobacco/surveillance/survey/ga ts/indonesia_report.pdf
Yang, T., Fisher, K.J., Li, F., Danaher, B.G. (2006). Attitudes to Smoking Cessation and Triggers to Relapse among Chinese Male Smokers. BMC Public Health, 6, 65.

Yudiono. Smoking problem and community in Malang District [Interview]. Vice of Health Promotions Division, Health Department Of Malang District; 28 June 2015 